\title{
Bilateral Keratomalacia Secondary to Diet Induced Vitamin A Deficiency in an Ethiopian Young woman: A Case Report
}

\author{
Kumale Tolesa Daba $^{1 *}$, Dagmawit Kifle ${ }^{1}$, Jafer Kedir Ababora ${ }^{1}$
}

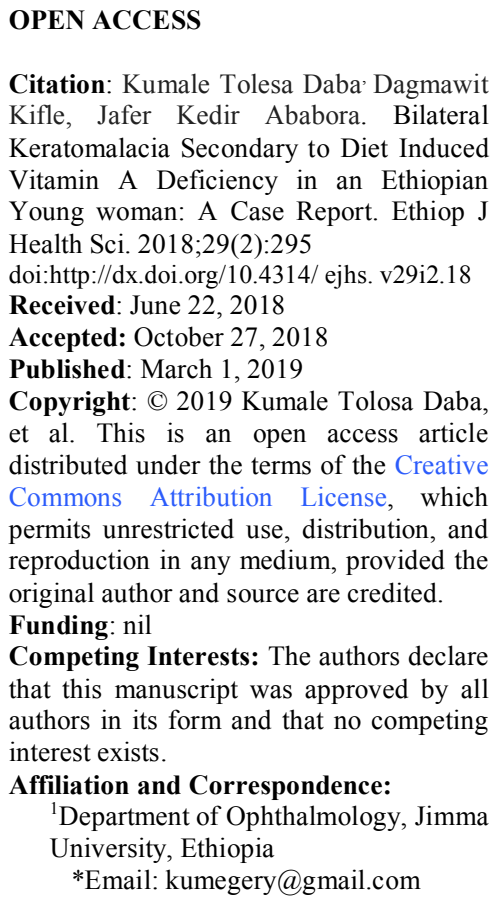

Citation: Kumale Tolesa Daba' Dagmawit Kifle, Jafer Kedir Ababora. Bilateral Keratomalacia Secondary to Diet Induced Vitamin A Deficiency in an Ethiopian Young woman: A Case Report. Ethiop J Health Sci. 2018;29(2):295

doi:http://dx.doi.org/10.4314/ ejhs. v29i2.18

Received: June 22, 2018

Accepted: October 27, 2018

Published: March 1, 2019

Copyright: (C) 2019 Kumale Tolosa Daba, et al. This is an open access article distributed under the terms of the Creative

Commons Attribution License, which permits unrestricted use, distribution, and reproduction in any medium, provided the original author and source are credited.

Funding: nil

Competing Interests: The authors declare that this manuscript was approved by all authors in its form and that no competing interest exists.

Affiliation and Correspondence:

${ }^{1}$ Department of Ophthalmology, Jimma

University, Ethiopia

*Email: kumegery@gmail.com

\begin{abstract}
BACKGROUND: Diet induced vitamin A deficiency is less commonly seen in otherwise healthy adults, due to large store of vitamin $A$ in the body. Night blindness is the commonest manifestation of vitamin $A$ deficiency in adults, whereas Keratomalacia is a rare manifestation.

CASE REPORT: A 27 years old Ethiopian woman came to Jimma University Department of Ohthalmology with a compliant of protrusion of the globe content of both eyes within a week, after having redness and fear of light of both eyes for 2 months. She was a mother of twins and had low socioeconomic status. On general examination, she was cachectic with enlarged parotid glands. On ocular examination, she was bilaterally blind and had dry ocular surface. There was bilaterally melted cornea with prolapsed uveal tissue. After several investigations she was diagnosed as bilateral Keratomalacia (stage X3B) secondary to diet induced vitamin $A$ deficiency. She was supplemented with vitamin $A$ and other nutritional supplementation. Topical lubricating drops and ointments were administered. Finally, conjunctival flap was done to preserve the globe.

CONCLUSION: Although it is rare, treating physicians should be aware of the occurrence of Keratomalacia in adults which is potentially blinding. Early recognition and treatment of vitamin $A$ deficiency at the stage of night blindness is essential in reducing blindness caused by Keratomalacia.

KEYWORDS: Keratomalacia, xerophthalmia, vitamin A deficiency, cornea and supplementation

\section{INTRODUCTION}

A 27 years old female patient came to Jimma University Department of Ophthalmology with a compliant of redness, tearing and fear of light in both eyes of 2 months duration. Three weeks prior to presentation, she developed extrusion of the left eye followed by the right eye within a week time. She had no history of trauma or surgery. There was also no recurrent redness before. She had very low income and her staple diet was bread only. She gave birth to twins 3 years back and they were living with her relatives because she failed to raise them by herself.
\end{abstract}


On systemic examination, her vital signs were stable. Her BMI was 13.9 (Weight $=33.4 \mathrm{~kg}$, Height $=1.55 \mathrm{~m}$ ), MUAC (Mid Upper Arm Circumference) was $16 \mathrm{~cm}$. She was cachectic on general appearance with enlarged parotid glands. On ocular examination, Vision was Hand Motion (HM) in the right eye and Light Perception (LP) in the left eye. There were matted cilia, dry conjunctival surface which was wrinkled and there was no tear meniscus on both eyes. The left cornea was melted totally, and uveal tissue was prolapsed. The right cornea was perforated inferiorly with uveal tissue prolapse and edematous superior part. The remaining peripheral corneal rim was thin, dry and lusterless bilaterally. The deep structures were not visible in both eyes (Figure 1).

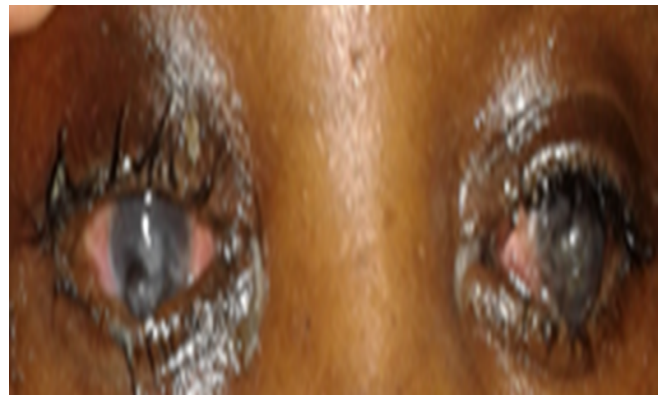

Figure 1: Corneal findings at presentation showing perforated corneas

Different investigations were made based on the above findings. $\mathrm{CBC}$ was in the normal range; ESR was $20 \mathrm{~mm} / \mathrm{hr}$; RBS was $124 \mathrm{mg} / \mathrm{dl}$; HIV test was non-reactive; liver and renal function tests were normal. The only positive finding was stool examination which showed ova of Ascaris lumbricoides.

With the diagnosis of Xerophthalmia stage X3B (Keratomalacia), she was admitted to the ward. She was supplemented with Vitamin A capsules $\left(200,000 \mathrm{IU}\right.$ orally on $1^{\text {st }}, 2^{\text {nd }}$ and $7^{\text {th }}$ day). Other supportive treatments including tear substitutes, ointments and prophylactic antibiotics. She was also given Mebendazole $100 \mathrm{mg}$ PO BID for 3 days for the intestinal parasite.

Since the right eye had better corneal rim for trial of corneal grafting, we did tectonic corneal graft for it, but there was wound dehiscence within few days because of further melting and fragility of the recipient rim. There was also localized wound infection at the dehiscence site. After the infection was controlled with aggressive antibiotics, the defect was repaired and supplemented with conjunctival flap. The protruded uveal tissue of the left eye was also covered with tight conjunctival flap (Figure 2). The patient is kept on follow up for possible future intervention after the inflammation subsides.

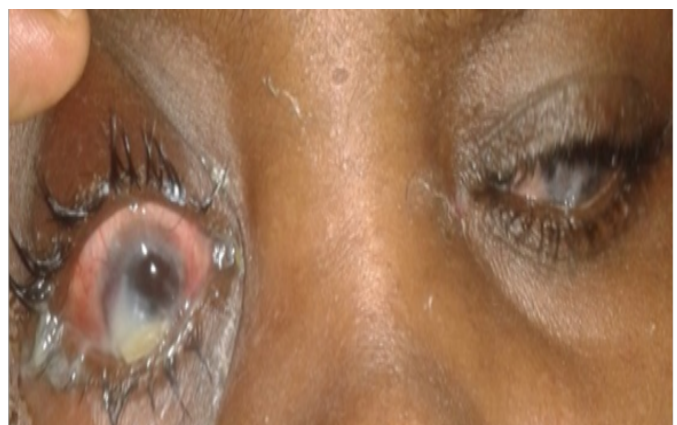

Figure 2: Post tectonic penetrating keratoplasty findings of right cornea showing the sloughed graft

\section{DISCUSSION}

Most case reports published todate discuss vitamin A deficiency in adults secondary to anorexia in psychiatric patients (2) or in chronic diseases of gastrointestinal system that interfere with vitamin A absorption, such aschronic liver disease, bile duct disorders, celiac disease, pancreatic insufficiency, Giardiasis, Crohn's disease and duodenal bypass surgery $(1,2)$. Most of the case reports demonstrate more of subclinical form of vitamin A deficiency where it is detected in dark adaptation testingor ERG (4).

Our patient had extremely poor socioeconomic status with poor nutritional history which may have contributed to the development of this severe form of xerophthalmia due to dietary deficiency, which was supposed to be unlikely in adults because of adequate storage in the liver. Based on the characteristic conjunctival and corneal findings, malnourished general appearance of the patient, laboratory evidence of intestinal parasitosis, poor nutritional history, 
higher prevalence of vitamin A deficiency in Ethiopia, and absence of any other local and systemic conditions to explain the ocular findings, she was diagnosed to have Xerophthalmia stage X3B (Keratomalacia). The limitation of this case report was that laboratory facilities for serum retinol level and conjunctival impression cytology were not available.

Diet induced Vitamin A deficiency in adults has been reported also after voluntary elimination of Vitamin A containing diet to prevent or reduce exacerbations of certain disease entities for longer period of time. According to Gombos et al's report (5) in the United States, a woman developed Keratomalacia after voluntarily eliminating all fresh fruit and vegetables from her diet to reduce exacerbations of her ulcerative colitis. As far as the authors' knowledge is concerned, there is no report of adult Keratomalacia secondary to dietary deficiency in Ethiopia.

Finally, we conclude that Keratomalacia secondary to dietary deficiency could be found in adults with poor nutritional history. Hence, awareness of this condition is recommended to detect the disease at the earliest stage and manage accordingly. Health education and other preventive measures that are currently focusing on under-five children may also need to include adults in areas of significant vitamin A deficiency prevalence.

\section{ACKNOWLEDGEMENTS}

We would like to thank Department of Ophthalmology, Jimma University, for their permission for writing this case report and providing logistics to manage the patient. Our sincerely thanks goes to JUDO staff for their support in the patient management.

\section{REFERENCES}

1. WHO global database on vitamin $A$ deficiency. Global prevalence of vitamin A deficiency in populations at risk 1995-2005.

World Health Organization. 2009

2. Jane Olver. Keratomalacia on a 'healthy diet'. British Journal of Ophthalmology, 1986, 70, 357-360.
3. Demissie T1, Ali A, Mekonen Y, Haider J, Umeta M. Magnitude and distribution of vitamin A deficiency in Ethiopia. Food Nutr Bull. 2010 Jun; 31(2):234-41.

4. Carney EA, Russell RB. Correlation of dark adaptation test results with serum vitamin A levels in diseased adults. J Nutr 1980; 110: 552-7.

5. Gombos GM, Hornblass A, Vendeland J. Ocular manifestations of vitamin A deficiency. Ann Ophthalmol 1970; 2:680.

DOI: http://dx.doi.org/10.4314/ejhs.v29i2.18 